\title{
Tensile behavior of humid aged advanced composites for helicopter external fuel tank development
}

\author{
Mihaela Condruz ${ }^{1 *}$, Alexandru Paraschiv ${ }^{2}$, Cristian Pușcașu ${ }^{2}$, and Ionuț Sebastian Vintilă ${ }^{l}$ \\ ${ }^{1}$ COMOTI - Romanian Research \& Development Institute for Gas Turbines, Composite Materials \\ Laboratory for Aeronautical Field and Space, 220 D Iuliu Maniu Av., Bucharest, Romania \\ ${ }^{2}$ COMOTI - Romanian Research \& Development Institute for Gas Turbines, Gas Turbine Special \\ Components. Physics and Mechanic Testing Laboratory, 220 D Iuliu Maniu Av., Bucharest, Romania
}

\begin{abstract}
Influence of humid aging on tensile properties of two polymeric composites was studied. The purpose of the study was to evaluate the suitability of the materials for a naval helicopter external fuel tank. Due to the application, the humid environment was kerosene and saline solution to evaluate the sea water effect on the composite tensile strength. The composite samples were immersed in kerosene for 168 hours, respective 1752 hours and in saline solution for 168 hours. Tensile tests were performed after the immersion. The composite sample tensile tests showed that kerosene and saline solution had no influence on the elastic modulus of the materials, but it was observed a slight improvement of the tensile strength of the two polymeric composites.
\end{abstract}

\section{Introduction}

Nowadays, fibre reinforced polymers (FRP) are a common material used in the aerospace field (for commercial/military aircrafts, helicopters, satellites etc.) due to their remarkable properties, such as strength, stiffness, low density and low coefficient of thermal expansion $[1,2]$. An important factor that stays behind the greater use of composites is the cost reduction experienced by carbon fibres [1]. Also, in case of aerospace applications, the reduction of weight, costs and fuel along with the increase of resistance and durability of the components are key aspects. Usually, in helicopter applications, composite materials are used to manufacture rotor blades, which ensure a significant weight reduction over aluminium and provide a better control over the vibration characteristics of the blades [3]. Excepting rotor blades, polymeric composites were integrated in tank assemblies for launch vehicles and helicopters. Researches were conducted to manufacture and validate external composite fuel tanks for helicopters to replace the metallic tanks [4]. External fuel tanks have been introduced to extend the range of a helicopter or to provide refuelling capacity at a remote location (it can provide at least an additional hour of flight depending on its capacity [5]). The first attempt to replace metallic external tanks was in the middle of 1970 and they were replaced by a hybrid model, a Composite Overwrapped Pressure Vessel -

* Corresponding author : raluca.condruz@comoti.ro 
COPV [4] (structure with a thin metal liner that acts as a leakage barrier, overwrapped by composite winding layers [6]). Afterwards, the COPV tanks were replaced by all composite external tanks. For researchers, an opportunity is represented by designing and manufacturing of an external composite fuel tank for F-35 Lightning II fighters [4,7]. An important aspect for designing and manufacturing external and auxiliary fuel tanks is to study structure's requirements and specification, which are stated in MIL-T-7378A [8].

Plastic fuel tanks should be fuel and environmental resistant (corrosion due to salt, moisture, ultraviolet radiation, thermal cycling in atmospheric conditions during normal service use and storage between $-54^{\circ} \mathrm{C}$ and $+71^{\circ} \mathrm{C}$ ) [8-11]. Durability of FRP can be affected by the contact with water or other fluids [12]. Most polymeric materials (in the form of a composite matrix or a polymeric fibre) are capable of absorbing relatively small but potentially significant amounts of moisture from the surrounding environment. The physical mechanism for moisture gain, assuming there are no cracks or other wicking paths, is generally assumed to be the mass diffusion following Fick's Law (the moisture analogue to thermal diffusion) [13]. The humid aging is one of the main causes of long-term failure of organic composites, which can affect the material in several modes: matrix microcracking, plasticization, hydrolysis, delamination, blistering, void growth, swelling, localized damage at the fibre-matrix interface [12-18]. Epoxy resin is known to have affinity for water [12], moisture has significant effects on physical and chemical properties of the resin as well as on the final composite structures performance, especially in longterm utilization [19]. The moisture absorption effect on polymeric composites mechanical properties had been studied for decades [20,21], but until now it's still a challenge to predict how a fibre reinforced composite will behave under a certain humid environment.

In early technical studies regarding environmental influence on composites, it was observed that in case of carbon/epoxy composites, the filament properties show very little environmental sensitivity, while epoxy resin is affected by the absorbed moisture and temperature effects which can lead to a change in failure mode [20], also the mechanical properties of composites are reduced after humid exposure, but all moisture effects were completely reversed upon re-drying the specimens [21]. Most of the authors studied water humid aging influence on polymeric composites [22-28] and as a general conclusion, the water causes mechanical properties degradation of thermosetting composites in case of extended period of immersion which can be noticed by matrix osmotic, cracking, swelling, mass loss, fibre exposure, chemical alterations etc. Many information about the effect of other fluids than water on composite properties are not available in the literature.

Souza et.al. [29] evaluated the creep behaviour of an E-glass/polyester composite in water and lubricant oil and it was observed that after 6 and 14 months of exposure, Young's modulus of the composite was reduced by $20 \%$ regardless the aging fluid when the test was performed at room temperature and in case of tests performed at $60^{\circ} \mathrm{C}$, the effects of immersion in lubricant oil were more severe than those after immersion in water. Areef [30] performed an experimental study on different solution absorption behaviour of a sandwich glass fibres/epoxy composite. The results showed a maximum value of mass gain of the samples immersed in organic solutions (kerosene, benzene) compared with samples immersed in other solutions, the samples immersed in distilled water had a minimum mass gain. Curliss [31] studied the effect of jet fuel JP-4 on thermoplastic and thermosetting composites. The thermoplastic matrix composites absorbed more fuel compared with the thermoset matrix composites, but the absorption appeared to be reversible without notable degradation of the matrix polymer. There was no evidence that any component of the matrix polymers was leaching into the jet fuel or that any fraction of the polymers was dissolving into the jet fuel. Taghavi [32] studied the diffusion of moisture into glass/epoxy, carbon/epoxy and carbon/polyimide composites immersed in water and kerosene. The glass epoxy composites showed a loss of about $21 \%$ of their transverse tensile strength after 100 
hours of immersion in $80^{\circ} \mathrm{C}$ kerosene, but after this point no further changes were observed up to 3500 hours. The transverse modulus was not significantly changed even after 3500 hours of immersion. For carbon polyimide composites, even after 3500 hours of immersion in $80^{\circ} \mathrm{C}$ kerosene neither the transverse modulus nor the strength changed.

The present research was focused on studying the kerosene and saline solution influence on the tensile properties of polymeric composite materials suitable for the manufacturing of an external fuel tank for a naval helicopter (IAR 330 PUMA).

\section{Experimental procedure}

Two types of polymeric composite laminates were manufactured for this experiment. The laminates were manufactured by using metallic moulds and an autoclave (curing process under temperature, vacuum, pressure). The composite consisted in two prepreg precursors, a HexPly M49/42\%/200T2X2/CHS-3K (referred as HexPly) and an EP 127-C20-45 T2 (referred as EP). The HexPly consisted in a twill $2 \times 2$ carbon fabric $3 \mathrm{~K}$ HS preimpregnated with an epoxy resin system (42\% resin content), and the EP was a twill $2 \times 2$ carbon fabric $3 \mathrm{~K}$ HTA preimpregnated with a blend of epoxy resin and cyanate ester $(45 \pm 3 \%$ resin content). After curing, samples were cut from laminates using a water jet cutting machine.

The samples dimensions $(250 \times 25 \times 3 \mathrm{~mm}$ with $1 \mathrm{~mm}$ thick tabs, type 3$)$ were established based on SR EN ISO:527-4/2000 [33], and ASTM D3039/D 3039M/2000 [34]. To ensure the water removal from the cutting process and the curing of the tabs, all the samples were post-cured in a vacuum assisted oven (curing cycle: heating for 35 minutes until $120^{\circ} \mathrm{C}$ were reached, heating rate of $2^{\circ} \mathrm{C} / \mathrm{min}$., 90 minutes at $120^{\circ} \mathrm{C}$ and oven assisted cooling).

All the samples were weighed before the immersion in saline solution and in kerosene at room temperature. To analyse the sea water effect on the composite tensile strength a saline solution was made by dissolving $35 \mathrm{~g}$ sea salt in a litre of distilled water to obtain a saline solution with $35 \%$ salinity (typical seawater salinity). The specimens were immersed in saline solution in an open glass recipient and in kerosene in a sealed container. The samples were kept at room temperature $\left(20 \pm 2^{\circ} \mathrm{C}\right)$ in kerosene for 168 hours ( 7 days), respective 1752 hours (73 days) and in saline solution for 168 hours. In Fig. 1 can be observed the immersed samples in kerosene and saline solution.

After immersion, the samples were wiped out with a cloth, weighed out to calculate the moisture content (or percent weight gain) of the material to establish if the material has kept its dimensional measurements (or has swollen).
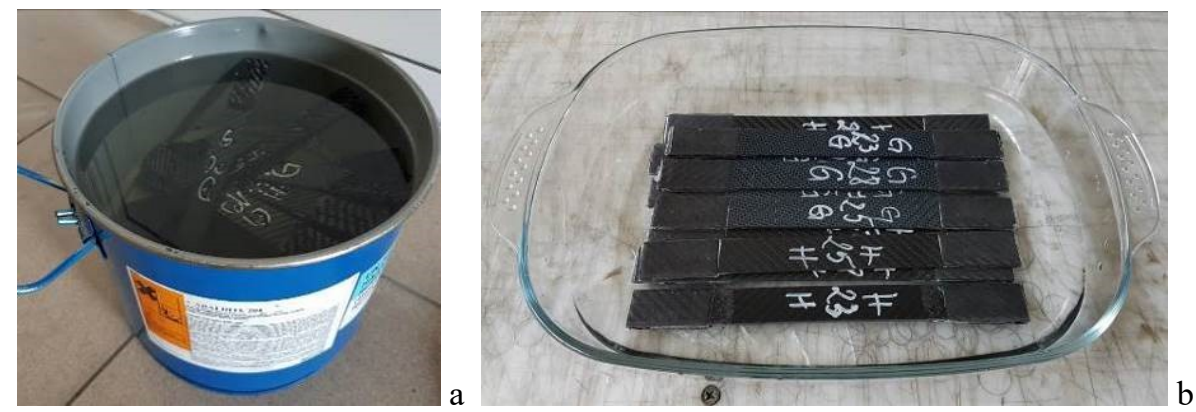

Fig. 1. Samples immersed in kerosene (a) and saline solution (b)

Tensile tests were carried out by using a Universal mechanical testing machine Instron 8802 with a displacement rate of $2 \mathrm{~mm} / \mathrm{min}$, according to SR EN ISO: 527-4 [33]. For evaluating the influence of the immersion in kerosene and salted water as a function of time it were used five specimens for each type of sample and for comparison were used 
reference samples from each lot of samples (not immersed). The fracture's modes were coded using typical modes from ASTM D3039/D 3039M/2000 [34], in Table 1 are presented the tensile test failure codes. In Table 2 can be observed the fracture's modes of composite specimens after tensile tests.

Table 1. Tensile test failure codes/typical modes [34]

\begin{tabular}{|l|l|l|l|l|l|}
\hline First character & Code & Second character & Code & Third character & Code \\
\hline Angled & A & Inside grip/tab & I & Bottom & B \\
\hline edge Delamination & D & At grip/tab & A & Top & T \\
\hline Grip/tab & G & $<1$ W from grip/tab & W & Left & L \\
\hline Lateral & L & Gage & G & Right & R \\
\hline Multi - mode & M & Multiple areas & M & Middle & M \\
\hline long. Splitting & S & Various & V & Various & V \\
\hline eXplosive & X & Unknown & U & Unknown & U \\
\hline Other & O & - & & - & - \\
\hline
\end{tabular}

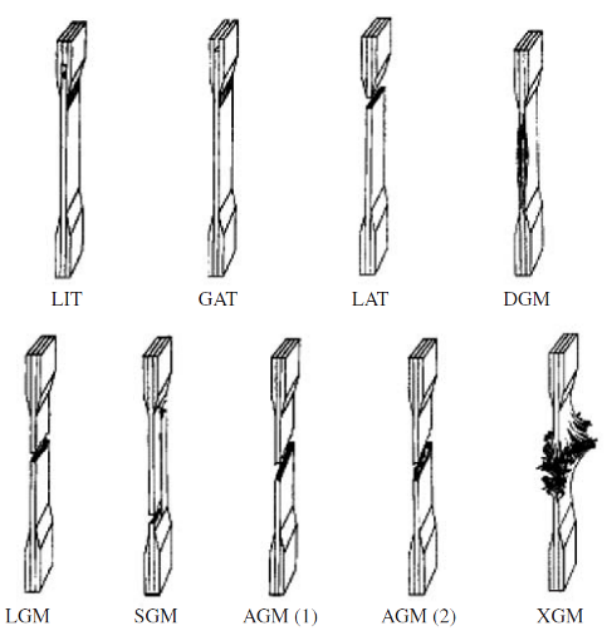

Fig. 2. Example representation of typical failure modes in tensile tests of composites [34]

\section{Results and discussions}

Both materials (HexPly and EP) showed a moist weight gain of $0,10 \%$ after the first 168 hours of immersion in kerosene and $0,16 \%$ after the 1752 hours of immersion in kerosene. Regarding the immersion in saline solution, the moist weight gain of both composites was $0,13 \%$ after 168 hours of immersion. The composite materials gained more weight after the immersion in saline solution compared with kerosene immersion, those were different results compared with the findings of Areef [30] who observed a higher weight gained by the composite immersed in organic solution (kerosene) then in distilled water (this could be influenced by the fact that the composite material used by Areef [30] consisted in glass fibre reinforced polymer and the samples were immersed only in distilled water not in distilled water with salt).

The moisture absorption of the HexPly and EP materials could increase after more hours of immersion, but the overall capacity of absorption of the composite wasn't the goal of this study. The composite samples maintained their dimensional measurements after the immersion in kerosene and saline solution immersion, they didn't modify the physical aspect of the samples (no peels or cracks were observed) and the polymeric materials 
weren't dissolved after immersion in saline solution or kerosene. Similar physical observations regarding the effect of jet fuel on polymeric composite materials were made by Curtis et.al. [31].

Table 2. Fracture's modes of composite specimens after tensile tests

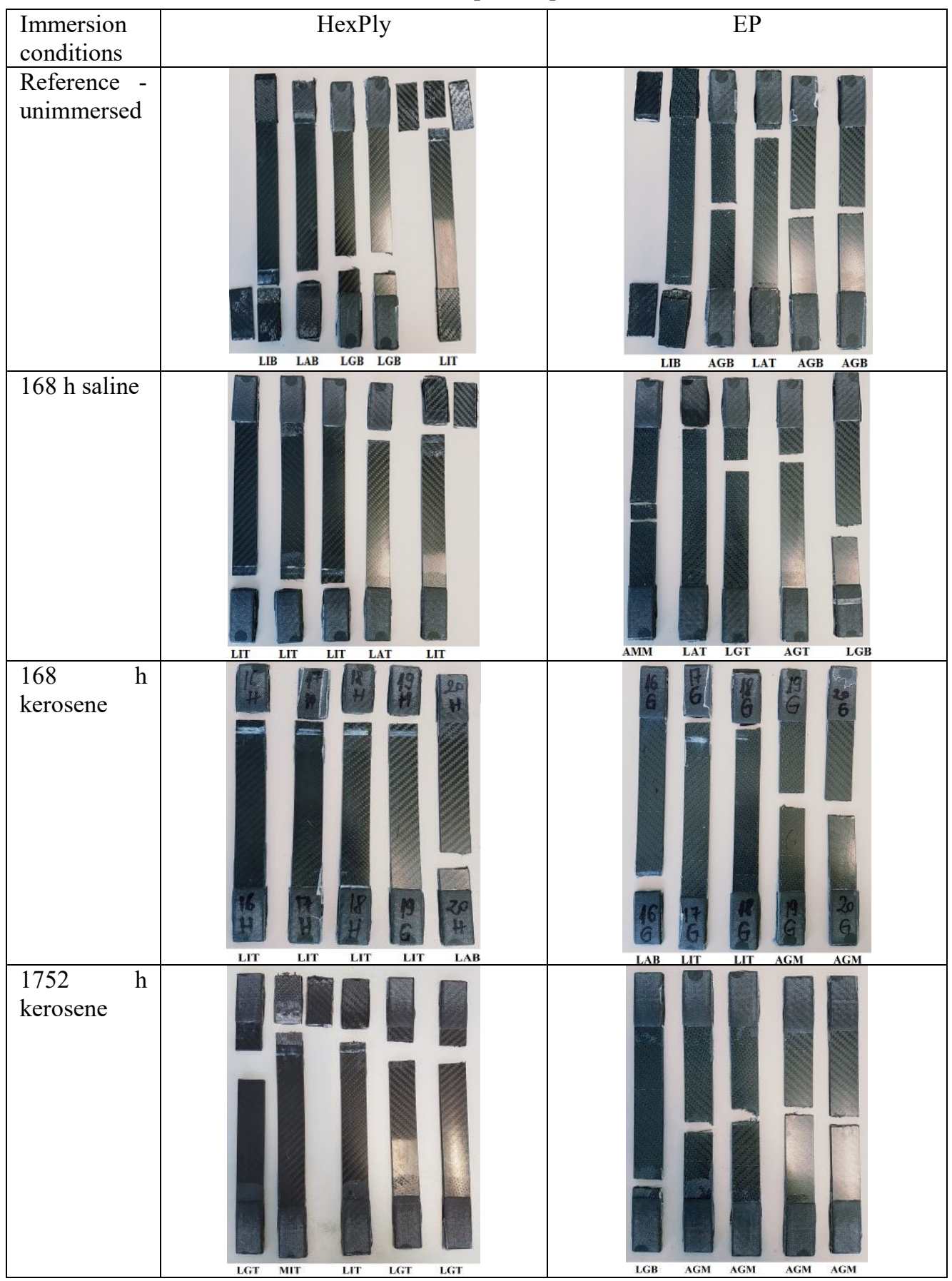

The tensile test results showed a slight increase of the tensile strength of laminates after each immersion phase in kerosene. 
In comparison with their reference samples, the HexPly specimens showed an increase of the tensile strength with $3 \%$ after 1752 hours of kerosene immersion at room temperature. EP specimens showed an increase of the tensile strength with 5\% after 1752 hours of kerosene immersion at room temperature.

A critical factor that can affect the tensile strength of the polymeric composite materials immersed in kerosene is the temperature of kerosene, fact proved by Taghavi [32] in his thesis, in which the specimens immersed for 100 hours in kerosene at $80^{\circ} \mathrm{C}$ showed a $21 \%$ reduction of transverse tensile strength, but after this point no further changes were observed up to 3500 hours. Thereby, in case of room temperature immersion for this period of time (max. $1752 \mathrm{~h}$ ), the kerosene had an opposite effect, it leads to a slight increase of tensile strength.

It can be concluded that kerosene absorption could slightly improve the tensile strength on short term due to modifications of the internal structure of the polymer and on long term it could weaken the polymer due to breaking of hydrogen bonds because a decrease number of hydrogen bonds is a factor which influences the mechanical properties of the polymeric matrix.

Regarding the influence of the immersion on saline solution the tensile properties of composites weren't affected by the saline solution immersion on short term $(168 \mathrm{~h})$, results confirmed also by the literature.

The studies regarding saline solution/seawater immersion of composite materials are limited, Roy Xu et. al. [28] observed that compression-after-impact strengths of the wet specimens were reduced by around $10 \%$ compared to the baseline dry specimens.

Visco et. al. [22] studied seawater absorption ability and mechanical performance of two glass-fibre reinforced composites with different thermoset matrices (isophthalic polyester, vinyl ester) and concluded that vinyl ester resin composite had a lower water diffusion coefficient but higher chemical stability, stiffness and strength after immersion in seawater than the isophthalic one.

Even if the tensile strength of the composite materials was increased it was observed that they maintain their Young's modulus value, $68 \mathrm{GPa}$ for HexPly samples, respective 62 $\mathrm{GPa}$ for EP samples. The elastic modulus could be maintained over a period of time in moist environment and afterwards it could be altered, the polymer becoming more brittle and easy to break.

Regarding the analysis of the tensile failure modes, it was observed that in case of HexPly samples, the majority presented a lateral inside grip top (LIT) typical failure mode followed by lateral gage top (LGT) failure mode, while EP samples presented an angle gage middle (AGM) failure mode followed by angle gage bottom (AGB) failure mode.

In Table 3 are specified the results of tensile test failure mode analysis of the composite specimens. It can be observed that in case of HexPly, the tested specimens present less scattered failure modes compared with the EP specimens. The predominant failure modes are typical for the matrix shear failure and brittle failure of polymeric matrix composites reinforced with fibres along with fibre pull-out.

In Fig. 3 a, b it can be summarized the influence of kerosene immersion on the tensile strength of the two composite materials and in Fig. 3 c can be observed the influence of saline solution on their tensile strength after 168 hours of immersion. 
Table 3. Results of the tensile test failure mode analysis

\begin{tabular}{|l|l|l|}
\hline Material & Typical failure mode & Number of specimens \\
\hline HexPly & LIT & 10 specimens \\
\hline HexPly & LGB & 2 specimens \\
\hline HexPly & LGT & 3 specimens \\
\hline HexPly & LAB & 2 specimens \\
\hline HexPly & LAT & 1 specimen \\
\hline HexPly & LIB & 1 specimen \\
\hline HexPly & MIT & 1 specimen \\
\hline EP & AGM & 6 specimens \\
\hline EP & AGB & 3 specimens \\
\hline EP & LIB & 1 specimen \\
\hline EP & LAT & 2 specimens \\
\hline EP & AMM & 1 specimen \\
\hline EP & LGT & 1 specimen \\
\hline EP & AGT & 1 specimen \\
\hline EP & LGB & 2 specimens \\
\hline EP & LIT & 2 specimens \\
\hline EP & LAB & 1 specimen \\
\hline
\end{tabular}
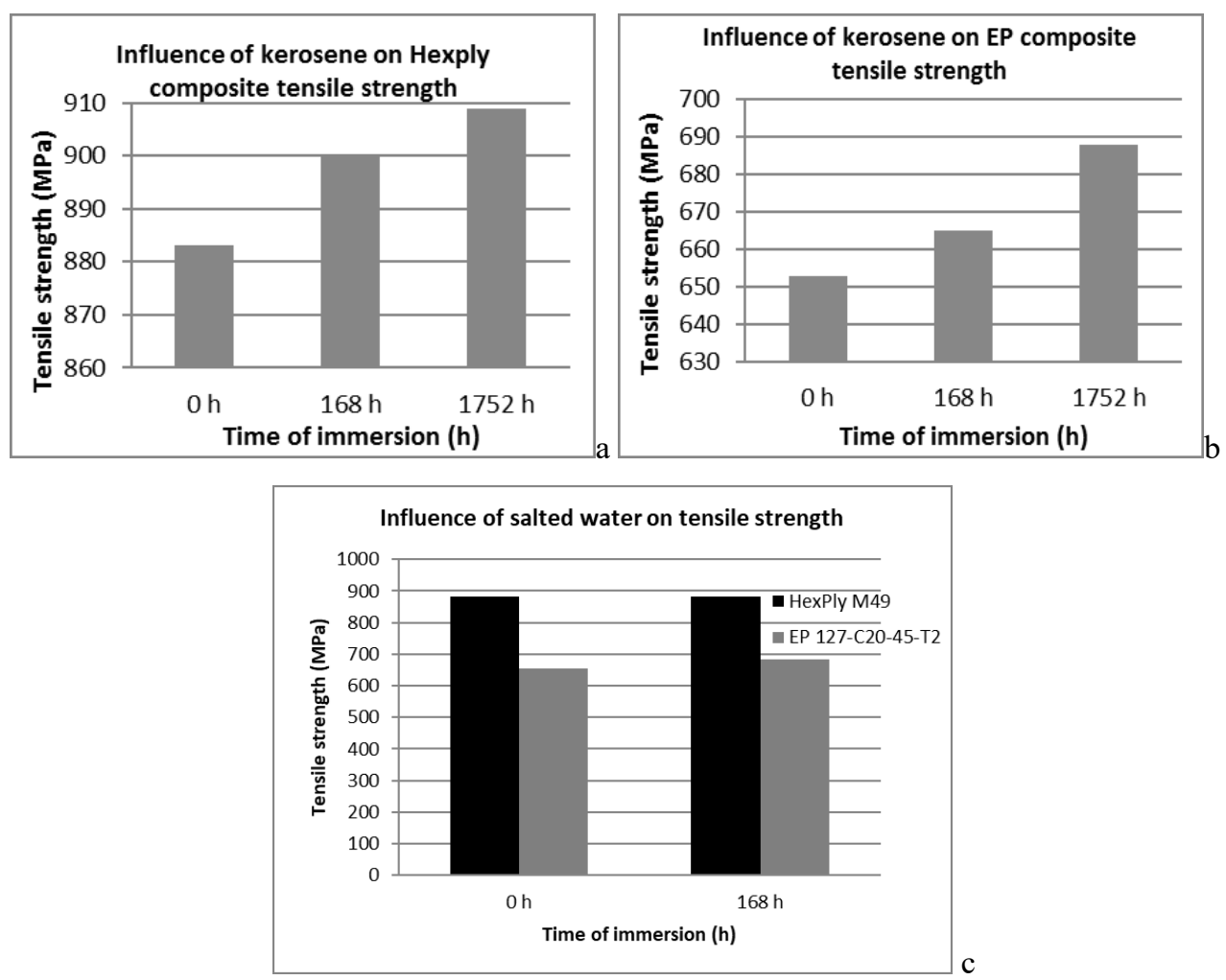

Fig. 3. Influence of kerosene and saline solution immersion on composite tensile strength: a) in case of HexPly; b) in case of EP; c) results in case of saline immersion of the composites 


\section{Conclusions}

The present study was focused on the tensile behaviour of two composite materials before and after aging in humid environment (saline solution and kerosene). The humid environments selected for the tests were kerosene due to the fact that jet fuels consist in kerosene and different types of additives and saline solution due to the fact that the tank is designed for a navel helicopter. Two types of composite laminates were tested and it was observed that kerosene slightly improves the tensile properties on short term exposure.

HexPly M49/42\%/ 200T2X2/CHS-3K showed an increase in tensile strength of $3 \%$ after 1752 hours of kerosene immersion and EP 127-C20-45 T2 showed an increase in tensile strength of $5 \%$ after 1752 hours of kerosene immersion. The saline solution exposure on short term $(168 \mathrm{~h})$ didn't influence the tensile properties of the HexPly M49/42\%/ 200T2X2/CHS-3K, but in case of EP 127-C20-45 T2 it was observed that the saline absorption increased the tensile properties with $5 \%$. However, it was observed that the composite laminates maintain their Young modulus $68 \mathrm{GPa}$ for HexPly samples, respective $62 \mathrm{GPa}$ for EP samples. Peeling, cracking or matrix dissolution of polymeric composite immersed in saline solution or kerosene weren't observed.

Due to the fact that it can't be predicted how a fibre reinforced composite will behave under a certain humid environment further studies will be made regarding the fuel compatibility with polymeric composites.

\section{Acknowledgment}

This study was carried out within Grant no. 293/2014, supported by the Romanian Minister of Research and Innovation.

\section{References}

[1] A.P. Mouritz, Introduction to aerospace materials, Woodhead Publishing, 303-337 (2012)

[2] R.J.H. Wanhill, Aerospace Materials and Material Technologies : Aerospace Materials, 1, Springer (2017)

[3] P.K. Mallick, Fiber-reinforced composites: Materials, manufacturing and design, CRC Press, 19 - 48 (2007)

[4] M.R. Legault, http://www.compositesworld.com/articles/carrier-capable-all-compositeexternal-fuel-tank(2) (2011)

[5] UH-60 A/L/M CRASHWORTHY EXTERNAL FUEL SYSTEM (CEFS) Brochure, http://www.robertsonfuelsystems.com/defense/crashworthy-external-fuel-system-cefs/

[6] M. Ren, X. Chang, H.Y. Xu, T. Li, Compos Struct, 160, 1339-1347 (2017)

[7] E. Elkhershi, The Telegraph, http://www.telegraph.co.uk/news/2016/03/18/inside-the-f35-lightning-ii---the-invisible-fighter-jet/ (2015)

[8] MIL-T-7378A. Military specification Tanks, Fuel, Aircraft, external, Auxiliary, Removable (1958)

[9] MIL-DLT-5578D. Detail Specification Tanks, Fuel, Aircraft, Self-sealing (2008)

[10] B. Wei, H. Cao, S. Song, Corros Sci, 53, 426-431 (2011)

[11] S. Lampman, Characterization and Failure Analysis of Plastics, ASM International, 146-152 (2003)

[12] J.A. Hinkley, J.W. Connell, Long-Term Durability of Polymeric Matrix Composites, Springer, 1-38 (2012) 
[13] MIL-HDBK-17-1F. Composite Materials Handbook, Polimeric Matrix Composites Guidelines for Characterization of Structural Materials, 1, (2002)

[14] B.C. Ray, J. Reinf. Plast. Compos., 25, (2016), pp. 1227-1240

[15] P. Vaddadi, T. Nakamura, R.P. Singh, Acta Mater, 51, (2013), pp. 177-193

[16] B.G. Kumar, R.P. Singh, T. Nakamura, J. Compos. Mater., 36, (2002), pp. 2713-2733

[17] S. Roy, Long-Term Durability of Polymeric Matrix Composites, Springer, (2012), pp. $181-236$

[18] I. Merdas, F. Thominette, A. TCharkhtchi, J. Verdu, Compos. Sci. Technol., 62, (2002), pp. 487-492

[19] E. Perez-Pacheco, J.I. Cauich - Cupul, A. Valadez-Gonzalez, P.J. Herrera-Franco, J. Mater. Sci, 48, (2013), pp. 1873-1882,

[20] C.E. Browning, C.E. Husman, J.M. Whitney, Moisture effects in epoxy matrix composites, Interim Report AFML-TR-77-171976, (1976)

[21] J.M. Augl, The effect of moisture on carbon fibre reinforced epoxy composite Mechanical property changes, Technical Report, Naval Surface Weapons Center, White Oak Laboratory, Maryland, USA, (1977)

[22] A.M. Visco, N. Campo, P. Cianciafara, Compos. Part A-Appl S, 42, (2011), pp. 123130

[23] P. Krishnan, M.S. Abdul Majid, M. Afendi, S. Yaacob, A.G. Gibson, Compos. Struct., 148, (2016), pp. 1-11

[24] A. Chilali, W. Zouari, M. Assarar, H. Kebir, R. Ayad, Compos. Struct., Article in press, (2017)

[25] V. Fiore, L. Calabrese, G. DI Bella, T. Scalici, G. Galtieri, A. Valenza, E. Proverbio, Compos. Part B-Eng., 93, (2016), pp. 35-42

[26] A.P.C. Barbosa, A.P.P. Fulco, E.S.S. Guerra, F.K. Arakaki, M. Tosatto, M.C.B. Costa, J.D.D Melo, Compos Part B-Eng., 110, (2017), pp. 298-306

[27] J. Naveen, T.P. Sathish Kumar, S. Satheesh Kumar, 3, (2014), pp. 1091-1095

[28] L. Roy Xu, A. Krishnan, H. Ning, U. Vaidya, Compos Part B-Eng, 43, (2012), pp. 2480-2486

[29] L.R. de Souza, A.T. marques, J.R.M. D’Almeida, Compos Struct, 168, (2017), pp. 285-291

[30] S.R. Areef, Eng. \& Technology, 26, (2008), pp. 1235-1239

[31] D.B. Curliss, The effect of Jet fuel exposure on advanced aerospace composites I:

Thermal and Chemical Analysis, Report, Materials Directorate, Wright Laboratory, Air Force System Command, Wright-Patterson Air Force Base, Ohio, USA, (1991)

[32] S.G. Taghavi, Moisture effects on high performance Polymer Composites, Master Thesis, Department of Chemical Engineering and Applied Chemistry, University of Toronto, 2000

[33] SR EN ISO:527-4/2000 Plastics - Determination of tensile properties-Part 4: Test conditions for isotropic and orthotropic fibre-reinforced plastic composites

[34] ASTM D3039/D 3039M/2000 Standard Test Method for Tensile Properties of Polymer Matrix Composite Materials 